\title{
Kategese, kategismusse en die belydenis van geloof in Genève in die dae van Calvyn
}

\author{
A D Pont \\ Universiteit van Pretoria
}

\begin{abstract}
Catechesis, catechisms, and the confession of faith in Geneva during the life of Calvin

In this article the catechetical instruction of the children of the faithful, that Calvin introduced in Geneva, is described. In the first place attention is given to the catechetical instruction as Calvin and Farel practised it during the years 1536-1538. On his return to Geneva in 1541 Calvin reorganised the catechetical instruction and expanded it. Attention is given to the catechetical material that was used and the role played by the parents, school and ministers in the religious education of the children. Finally the quality of Calvin's work is briefly discussed.
\end{abstract}

\section{INLEIDING}

Met die oprigting van kerke en gemeentes deur die reformatore in die sestiende eeu moes in baie opsigte nuwe reëls neergele word om die lewe van die gelowiges te orden en die gemeentelike sake te struktureer. Dit het beteken dat nuut gedink en bepaal moes word want die meeste Rooms-Katolieke gebruike was nie aanvaarbaar nie. Een van die sake wat heelwat aandag geniet het, was die godsdienstige onderrig en opvoeding van die kinders van die gelowiges. Dit was en is tot vandag toe 'n saak van groot gewig omdat dit, in 'n hoë mate, die kwaliteit van die gemeente van die toekoms bepaal. Nou is dit interessant om vas te stel hoe die kerkvader Johannes Calvyn hierdie saak in Genève hanteer het. Dit bly van belang omdat so baie van die beslissings wat Calvyn in die sestiende eeu geneem het vandag nog die ritme van die lewe van die kerk bepaal. 


\section{CALVYN IN GENeVE 1536-1538}

Toe Calvyn deur Guillaume Farel oorreed is om in Genève te kom werk, was Calvyn se Institusie pas van die pers want dit het in Maart 1536 verskyn. Daarin het Calvyn die breë lyne getrek van die boodskap van die Skrif. As hy in Genève aankom, stel hy vas dat die Roomse godsdiens afgeskaf is, dat die kerkgeboue in die stad beskikbaar gestel is vir die diens van die prediking en dat drie predikante in Genève gewerk het. Vir Calvyn was dit egter nie voldoende nie (OC V.313-362; OC IX.891 \& OC XXI.25), omdat hy dan reeds 'n duidelike beeld van die kerk het (Inst 1536 II.4.21). Vir Calvyn was die kwaliteit van die gelowiges wat die gemeente vorm van wesenlike belang. Objektief gesproke word dit bepaal deur die vraag of hulle die uitverkorenes van God is en subjektief of hulle ware gelowiges is. Terwyl dit so is dat die uitverkorenes slegs aan God bekend is en hulle uitverkore-wees nie absoluut deur menslike maatstawwe vasgestel kan word nie (Inst 1536 II.4.25), stel Calvyn tog dat die uitverkorenes herken kan word omdat die geloof, wat 'n genadegawe van die Gees is, 'n teken van die uitverkiesing is (Komm Heb 6:5 in OC LV.7; Komm Rom 10:17 OC XLIX.206). Soos hy dit stel (Komm Fil 1:6, OC LIII.9): 'Die feit dat die Here ons effektief tot Hom geroep het deur sy Gees, is vir ons 'n teken van ons verkiesing.' Daarom argumenteer Calvyn dat die uitverkorenes, wat die kerk is, geken kan word deurdat hulle soos en saam met die kerk hulle geloof in dieselfde God en Christus bely. So kan duidelik onderskei word tussen die gelowiges en die ongelowiges. Dit is duidelik dat Calvyn nie 'n onderskeid maak tussen gelowiges, uitverkorenes en lidmate van die kerk nie. Dit lê waarskynlik dáárin dat vir Calvyn die instemming met die aanvaarding van die aanvaarde geloofsbelydenis van die kerk die toets is van lidmaatskap en gelowig-wees. Hy het dus 'n objektiewe norm hanteer en nie 'n subjektiewe norm, naamlik die kwaliteit van die geloof van die gelowiges, soos dit gebruiklik geword het in die na-Calvyn Calvinisme nie. Dit hang waarskynlik saam met die feit dat Calvyn nooit 'n ordo salutis geleer het nie maar wel klem gelê het op die kerklike dissipline waar vasgestel moes word of die gelowiges/lidmate tot die nagmaal toegelaat kon word. Maar ook daardie toets was 'n objektiewe en nie 'n subjektiewe toets nie.

Calvyn se opvatting is dan verder dat 'n duidelike onderskeid gemaak moet word tussen die uitverkorenes/gelowiges aan die een kant en die ongelowiges aan die ander kant. Veral waar hy aan die begin van sy dienswerk in Genève gestaan het, was dit vir hom 'n saak van belang. Calvyn het dan reeds in sy Institusie 1536 (II.4.26) die notae fidelium uitgespel waar hy gesè het: 
Maar hoewel die uitverkorenes nie met geloofsekerheid deur ons herken kan word nie, beskrywe die Skrif tog vir ons bepaalde vaste tekens, soos tevore gesè is, waarvolgens ons die uitverkore kinders van God van verwerpte vreemdelinge kan onderskei in soverre as wat dit sy wil is dat hulle deur ons herken moet word: volgens die een of ander oordeel van liefde moet al die mense as uitverkorenes en lede van die kerk beskou word wat sowel in geloofsbelydenis as voorbeeld van lewe en deelname aan die sakramente, dieselfde God en Christus as ons bely....

Die eerste van die notae fidelium is dan die confessio fidei. Wat dit beteken word onder andere duidelik uit die wyse waarop Calvyn die kategese van die kinders van die gemeente reël.

Om die gemeente in Genève na sy insigte te orden, het Calvyn 'n duidelike program opgetrek, die Articles concernant l'organisation de l'église et du culte à Genève, proposés au Conceil par les Ministres (OC X/1.5-14). Hierdie program was die resultaat van 'n versoek van die Raad aan Farel in 1536 om die Raad te voorsien van 'n program wat bedoel is om 'L'unité de la ville et afin d'unir les citoyens dans la foi en Christ' te bevorder (Rilliet A et Dufour 1878:201). Na Calvyn se aankoms in Genève is aan die versoek aandag gegee en so ontstaan die Articles, wat op 10 November 1536 aan die Raad voorgele is en deur hulle oorweeg en goedgekeur is op 15-16 Januarie 1537.

In die Articles word dit duidelik dat dit vir Calvyn nie voldoende is dat die burgers van Genève op 'n algemene vergadering van 25 Mei 1536 onderneem het om volgens die voorskrifte van die evangelie te leef nie (Parker 1975:57). Hy is van oordeel dat geen gemeente reg georden is as daar nie voorsiening is vir die reëlmatige viering van die nagmaal nie. Daarby is hy van oordeel dat niemand na die nagmaal mag gaan sonder geloof en sonder 'n bepaalde eerbied daarvoor nie. Daarom stel hy in die Articles dat vier dinge nodig is om die gemeente reg te orden. Dit is dan:

a) die handhawing van die dissipline en die ekskommunikasie, want daardeur kan diegene tereggewys en geweer word wat nie in gehoorsaamheid aan die Woord van God leef nie;

b) die sing van Psalms in die godsdiensoefening sodat almal saam tot God kan bid en sy lof kan sing en so eenparig hulle dankbaarheid kan betuig;

c) die noodsaaklikheid om die kinders van kleins af te onderrig sodat hulle sal weet wat hulle glo en dat die evangeliese leer nie vergeet sal word nie, maar die inhoud daarvan oorgedra sal word van vader na seun. So sal die gemeente ook die suiwere leer handhaaf; 
d) die belangrikheid om die huwelik reg te orden en dit te suiwer van die Roomse dwalings wat dit omring.

Hier blyk dus dat die handhawing van die dissipline en die kategetiese onderrig vir Calvyn twee belangrike steunpunte is waarop die gemeente gebou moes word. Die dissipline is veral belangrik omdat daardeur verseker kan word dat net werklike lede van die liggaam van Christus deel sal he aan die nagmaal. Die dissipline is op sy beurt moontlik nadat al die gelowiges in die openbaar gestel het dat hulle soos en saam met die kerk glo deur die aanvaarde geloofsbelydenis van die kerk te aanvaar. Juis omdat die geloofsbelydenis die grense van die kerk trek, is dit noodsaaklik dat almal dit sal aanvaar want so word die grenslyn tussen die gelowiges, diegene wat as lidmate aanvaar kan word, en die ongelowiges duidelik getrek. Terselfdertyd kom die kategese ook na vore want Calvyn verwag dat die gedoopte kinders van die gelowiges op so 'n manier onderrig moet word dat hulle in die openbaar bewys van hulle geloof kan gee, en so kan stel dat hulle ook soos en saam met die kerk dieselfde God en Christus bely. Die geloofsbelydenis waarna verwys word is die belydenis wat Calvyn en Farel ook op 10 November 1536 aan die Raad voorgelê het (OC XXII.77 gee die Franse teks en OC V.355 die Latynse teks).

\section{REēI INGS IN VERBAND MET DIE KATEGESE}

In die Articles het Calvyn 'n duidelike orde vir die kategese neergelê. Sy uitgangspunt is dat dit bo alle twyfel vasstaan dat die gedoopte kinders van die gelowiges hulle geloof moet bely. Soos hy dit stel:

Vir hierdie doel is in die ou tyd 'n spesifieke kategismus gebruik om hulle in te lei in die beginsels van die christelike godsdiens wat ook'n formule vir (hulle) getuienis b zvat wat elkeen kon gebruik om sy christenskap te betuig (formulayre de tesmoignage dont ung chacun usoyt pour declairer sa crestienté). Die kinders is individueel onderrig aan die hand van die kategismus en moes dan na die kerk kom om bewys te lewer van hulle geloof (testiffier a leglise leur foy) want met hulle doop was hulle nie in staat om daarvan te getuig nie. Want ons bemerk dat die Skrif altyd belydenis met geloof verbind en dit sê aan ons dat as ons waarlik met die hart glo, dit reg is dat ons met die mond moet bely van daardie verlossing waarin ons glo.

Die kategismus waarna Calvyn verwys is sy eerste kategismus, Instruction et Confession de Foy dont on use en l'Eglise de Genève (in OC V.322 word die Latynse teks van 1538 gegee en in OC XXII die Franse teks van 1537). Wat die inhoud betref, volg 
die Kategismus hoofsaaklik die orde van die Institusie 1536. Die verskil is dat die Instruction begin met sewe artikels oor die kennis van God en die mens. Daarna word dieselfde materiaal behandel as wat voorkom in die Institusie 1536, behalwe dat die hoofstuk oor die vyf valse sakramente weggelaat word. Sommige leerstukke soos dié oor die regverdiging deur die geloof alleen, bekering en weergeboorte word anders hanteer as in die Institusie 1536. Tog is die Institusie 1536 die hoofbron vir die Instruction wat in 'n sekere sin gesien kan word as 'n voorloper van die Institusie 1539.

Die reëling wat Calvyn vir die kategese tref is die volgende:

a) Allereers moet die kinders deur hulle ouers onderrig word en die ouers moet die Instruction as 'n handboek gebruik;

b) Op vasgestelde tye sal die kinders deur die predikante ondersoek word en indien nodig sal die predikante hulle dan 'n vollediger onderrig gee totdat hulle kennis voldoende is;

c) Daarna sal die kinders voor die predikante belydenis van geloof aflê en daarna toegelaat word om deel te neem aan die viering van nagmaal.

Dit wil voorkom asof Calvyn hier die orde volg wat in Basel gebruik is. In die Baselse kerkorde van 1529 (Richter 1846:122) word onder Der Lutpriesters ampt gestel dat die kinders in die godsdiens en ten opsigte van die Christelike lewe onderrig moet word. Die predikant en 'n diaken moes vier maal per jaar alle kinders van die ouderdomme van sewe tot veertien jaar byeenroep en vasstel of hulle kan bid en of hulle die wet van God ken. Daarby moes hulle spesifiek oor die sakramente onderrig word. Die nuwe element wat Calvyn invoer, is dat die kinders 'n geloofsbelydenis voor die predikante moes aflè.

Vir Calvyn was dit vanaf 1537 'n uitgemaakte saak dat die kategese na 'n aflegging van 'n geloofsbelydenis moes lei (Institusie 1559 IV.19.13). Hier het Calvyn, net soos die ander reformatoriese vadere 'n nuwe pad gegaan. Gedurende die Middeleeue het die Roomse kerk die kategese van die kinders volledig links laat lè. Van't Veer (1942:146) stel dat gedurende die Middeleeue geen kategetiese materiaal vir die gebruik van kinders gepubliseer is nie. Die kategetiese werke wat daar was, was vir die priesters bedoel wat dit by die bieg en absolusie gebruik het. Die gewone lidmaat kon dit ook gebruik om sy kinders te onderrig.

Nadat Calvyn in 1538 saam met Farel uit Genève verban is, is omtrent alles wat hy in drie jaar opgebou het, weer afgebreek (OC XI.367: Calvyn se brief aan Myconius 14 Maart 1542). Veral die kategetiese onderrig van die kinders is daardeur geknou. Nie alleen is Calvyn se Instruction vervang deur 'n kategismus van Megander ('n verkorte weergawe van Leo Judae se kategismus van 1534) nie, maar daar is 
selfs ' $n$ ander kategismus gebruik wat bepaalde Rooms-Katolieke opvattings na vore gebring het. Die saak het so ver gegaan dat die Raad van Bern op 3 Januarie 1540 twee manne na Genève gestuur het 'pour les affaires de la religion' en omdat die kategese van die kinders so verwaarloos is (Herminjard 1878-1897:158-160).

\section{CALVYN KEER TERUG NA GENAVE}

In September 1541 het Calvyn na Genève teruggekeer op grond van 'n uitdruklike versoek van die Raad (OC XXI.282: Annales Calviniani, Mardi 13). Voor sy terugkeer het Calvyn twee voorwaardes daarvoor gestel en dit was dat naas 'n behoorlike reëling vir die kategese die kerklike dissipline ook onverkort gehandhaaf sal word (OC XXI.64: Colladon, Vie de Calvin). Om dit te kan doen het Calvyn 'n behoorlike kerkorde opgestel wat in November 1541 deur die Raad aanvaar is. In die kerkorde word daar sorgvuldige reëls vir die kategese neergele (Pont 1981:41). Hier word dan bepaal:

Alle burgers en inwoners moet hulle kinders Sondagmiddag na die bogenoemde kategismusonderrig bring of stuur sodat hulle onderrig kan word oor die kategismus wat vir hierdie gebruik opgestel is. In samehang met die onderwysing in die leer, sal hulle oor die behandelde stof ondervra word om te sien of hulle dit goed verstaan en onthou het.

As 'n kind voldoende onderrig is...moet hy plegtig die inhoud daarvan weergee en dan ook beıydenis van geloof in teenwoordigheid van die gemeente aflê.

Die kategismus waarna hier verwys wor 1, is nie weer die Instruction van 1537 nie, maar 'n nuwe kategismus wat Calvyn in 1541, na sy terugkeer uit Strasbourg opgestel het (OC IX.894). Hierdie kategismus is aan die einde van 1541 of die begin van 1542 gedruk (OC XI.364) en 'n Latynse vertaling daarvan is in 1545 gedruk. Dit het die titel gedra: Le catechisme de l'eglise de Geneve: c'est dire, le Formulaire d'instruir les enfans en la Chrestienté: faict en maniere de dialogue, ou le Ministre interrogue et l'enfant respond. Hierdie kategismus wat van die vraag- en antwoord-metode gebruik maak, bestaan uit 374 vrae an antwoorde. Dit behandel allereers die geloof met 'n uiteensetting van die Apostolicum (132 vrae en antwoorde) en daarna die wet van God (100 vrae en antwoorde), die gebed met 'n uiteensetting van die Ons Vader (62 vrae en antwoorde) en die Woord van God waarby die sakramente bespreek word ( 77 vrae en antwoorde). Die kategismus het ver buite die grense van Genève groot invloed uitgeoefen (Simpson 1981:ii). 
Saam met die kategismus het Calvyn nou baie meer presies die pligte van almal wat by die kategese betrokke moet wees, uitgespel. In die eerste plek is die taak van die ouers uitgespel. Volgens Calvyn het die ouers by die doop van hulle kinders hulleself verbind om hulle kind in die leer van die kerk te onderrig. Vir Calvyn was dit die taak van die hoof van die huisgesin en in sy kategetiese onderrig moes die bediendes ook betrek word (OC X/1.52: Ordonnances sur la police des eglises de la campagne, 3 Feb 1547 asook CO XXIX.84; CO XXVI.37). Calvyn sien dit so dat die godsdienstige onderrig van die kinders 'n taak is wat God aan die ouers gee (OC XXVII.109: Komm Deut 11:8-15; OC XXXI.327: Komm Ps 33:6 en OC XXIII.395: Komm Gen 28:18) wanneer Hy die huwelik met kinders seën. Daarom is dit 'n merkteken van 'n regte ouer dat hy die kategetiese onderrig van sy kinders nie verwaarloos nie (OC XXXV.574; OC XXVI.483: Komm Deut 6:15-19 en Institusie 1559, IV.16.32).

In sy bespreking van dié verantwoordelikheid verwys Calvyn na die genadeverbond en die kinderdoop. Deur die kategese s6 op die fondament van die genadeverbond te bou gee Calvyn 'n nuwe dimensie aan die kategese. Hoewel uiteindelik die ouers in Calvyn se Genève nie baie positief op hierdie opdrag gereageer het nie, het Calvyn steeds die ouers se verantwoordelikheid ten opsigte van die kategese beklemtoon.

In die tweede plek het Calvyn nou die taak van die predikant ten opsigte van die kategese uitgebrei. Van die predikant word nou verwag om Sondagmiddag 'n kategesepreek te hou en die kinders ook nog verder te onderrig. So word die kategese deel van die lewe en werk van die kerk.

Die ouers en ook die skool moes toesien dat hulle kinders Sondagmiddag om twaalf uur by die kerk is en diegene wat hierin versuim moes deur die kerkraad aangespreek word. Kampschulte (1869:Bd 1, 459) sê hiervan: 'Die sonntägliche Katechese erlangte in Genf eine bedeutung wie in keiner andern Kirche...Sie war die eigentliche Schule ächt calvinischer Gesinnung und Denkweise.'

In die derde plek het Calvyn ook vir die skool 'n plek in die kategetiese onderrig ingeruim; dit ook omdat ten tyde van die reformasie die skool as 'n belangrike instrument vir die godsdienstige opvoeding en onderrig van die kind beskou is. Dit is interessant om vas te stel dat die hele skoolonderwys in Genéve gebou was op die kennis van God en sy Woord (Van't Veer 1942:88-106).

So het Calvyn die ouers, die kerk en die skool laat saamwerk om die kinders se kategese so goed as moontlik te laat verloop. Die doel van die kategese was om die kinders te bring tot by die afle van geloofsbelydenis in die gemeente. Daarvoor was daar 'n geleentheid voor die kwartaallikse viering van die nagmaal (Schwarz 1962: 330). Die vraag oor die ouderdom van die kinders wat toegelaat is om belydenis 
van geloof af te lê, word nogal verskillend beantwoord. Peter (1965:178) meen dat die ouderdom van elf tot twaalf jaar was terwyl Pfisterer (1938:1) weer praat van 'n ouderdom van tien tot vyftien jaar. Dit wil voorkom dat daar nie 'n presiese ouderdom was nie maar dat die kinders, na kategese, vanaf hulle elfde jaar toegelaat is om belydenis van geloof af te lê.

'n Interessantheid is dat Calvyn se kategismus wat as handboek by die kategese gebruik is, nie gebruik is as 'n stuk werk wat gememoriseer moes word nie. Die gemiddelde ouderdom van die katkisant het so-iets buitendien uitgesluit. Die materiaal wat finaliter gememoriseer moes word, word in 1553 met die titel, La maniere d'interroguer les enfaus qu'on veut recevoir a la cene de nostre seigneur Jesus Christ, as 'n addendum by die kategismus gepubliseer.

Hierdie opsomming van Calvyn se kategismus van 1541 of 1542 is waarskynlik ook gebruik as die 'Kortbegrip' wat die katkisante moes memoriseer (OC VI.147. 160). Peter (1965:171-205) het uitvoering op die gebruik van die verkorte kategismusse in Genève ingegaan. Peter (1974:85) toon aan dat Calvyn, in medewerking met Clement Marot, reeds so 'n verkorte kategismus gepubliseer het onder die titel, La manyere de faire prieres awx eglises francoyses, etc. te Rome, dit wil sê Strasbourg, op 15 Februarie 1542.

Calvyn het egter ook 'n catechisme élémentaire geskryf getitel Institution puerile de la doctrine faicte par manyere de dyalogues (Peter 1974:86). Die eerste uitgawe wat waarskynlik uit 1540 dateer het verlore gegaan en slegs die tweede uitgawe van 1542 het behoue gebly. Die eerste uitgawe is dus gepubliseer terwyl Calvyn in Strasbourg gewerk het. Dit verklaar waarom dit 'n sekere verwantskap vertoon met Martin Bucer se Ein Kürtzerer underricht für die gar Jungen und einfeltigen wat gepubliseer is as 'n bylaag by Bucer se Katechismus van 1537 (Stupperich 1987:175sq). Stupperich (1987:548) verwys ook na 'n Franse vertaling van Bucer se kategismus wat in 1542 in Strasbourg gepubliseer is. As Bucer en Calvyn se verkorte kategismusse vergelyk word, word dit duidelik dat Calvyn se werk nogal afhanklik is van Bucer se werk, want dit het dieselfde struktuur en die inhoud is basies dieselfde. Dit kan dus gesê word dat Calvyn gebruik maak van die kategetiese tradisie wat Bucer vanaf 1537 in Strasbourg gevestig het.

Peter (1965:182sq) toon aan dat daar ongeveer vier derglike 'kort begrip'-kategismusse in Genève gebruik is. Elkeen van dié het ook die La maniere d'interroguer les enfans bevat wat die vrae en antwoorde gee wat die katkisant moes hanteer wanneer hy voor die gemeente belydenis van geloof aflê. Die vrae wat hier gevra word toets die katkisant se kennis van die geloof van die gemeente en probeer vasstel of hy soos en saam met die kerk glo. Dit hang saam met Calvyn se opvatting: 'Domi- 
nus per evangelium nos vocat: nos vocanti per fidem respondemus' (OC XLIX.11 Komm Rom 1:5).

Geloof, soos Calvyn dit uitle, kan alleen bestaan as die inhoud van die evangelie geken en aanvaar word (Brunner 1925:117). Hier word weer duidelik wat Calvyn bedoel het in die Institusie 1536 (II.4.26) waar hy gestel het: '...volgens een of ander oordeel van liefde moet al die mense as uitverkorenes en lede van die kerk beskou word wat sowel in geloofsbelydenis as voorbeeld van lewe en deelname aan die sakramente dieselfde God en Christus as ons bely....'

Die kategese van die kinders kom tot sy voltooiing wanneer die katkisante voor die hele gemeente die voorgeskrewe vrae oor hulle kennis van die geloof van die kerk kan antwoord. Op grond daarvan word hulle dan toegelaat om deel te neem aan die viering van die nagmaal (Schwarz 1962:330). Met die aflê van die geloofsbelydenis word 27 vrae aan die katkisante gestel. Die vrae toets sorgvuldig die katkisant se kennis van die kerklike leer. So moet die katkisant, in antwoord op vraag 4, 'n uitgebreide opsomming van die Apostolicum ken wat as sodanig ook 'n interessante weergawe en interpretasie van die simbool is. Daarnaas volg daar enkele vrae oor die wet van God (5-10), dan twee vrae oor die verlossing deur Jesus Christus, dan enkele vrae oor die gebed (13-17), terwyl dan oor die sakramente gehandel word (19-25) en ten slotte oor die geloofsekerheid. Miskien kan net die laaste vraag aangehaal word om iets van die teologiese denke wat hier na vore kom te illustreer:

Vraag 27. Hoe kan ons hierdie geloof kry?

Antwoord. Ons ontvang die geloof deur die Heilige Gees wat in ons hart is en ons verseker van die beloftes van God wat in die evangelie aan ons geskenk word.

As die vraagstelling voltooi is, sluit die predikant die seremonie af met die woorde: 'Gaan dan in vrede en mag God sy genade in julle en in ons wat almal sy kinders is, al meer en meer vermeniguldig.' Daarop antwoord die kinders: 'Dit sal so wees deur ons Here Jesus Christus' (Jacobs 1949:71).

Interessant is dat Calvyn hier nie die voorbeeld van Bucer volg nie. Bucer het, vanweë die druk van die Anabaptiste, van die saak van die aflè van die geloofsbelydenis 'n hele seremonie gemaak. In die Siegenhainer Zuchtordnung (Stupperich 1987:264) word bepaal dat nadat die predikant die katkisante oor die vernaamste stukke van die leer ondervra het en hulle hulle 'offentlich Christo dem Herren und seiner Kirchen ergeben haben', sal hy hulle met die oplegging van hande in die Christelike gemeenskap bevestig. Daarby sal die kinders na die nagmaal genooi word met die vermaning dat hulle getrou sal wees in hulle gehoorsaamheid aan die evangelie, dat hulle hulle sal onderwerp aan die Christelike tug en straf en aan die pastorale sorg. Hierdie gebruik wat ook uitgespel word in die Ordnung der Firmunge 
und der Hendt aufflegen (Stupperich 1987:310-313) het wye navolging in die Calvinistiese kerke in Nederland en Duitsland gevind.

Hier is duidelik ' $n$ verskil in interpretasie en teologiese waardering. Dit is duidelik dat vir Calvyn die doel van die kategese is om die kinders iets te leer sodat hulle met begrip na die nagmaal kan gaan. Die kinders word in die kategese onderrig sodat hulle soos en saam met die kerk, die gelowige gemeenskap, die geloofsbelydenis kan aanvaar. Bucer, so lyk dit, wil met die kategese ook 'n bepaalde vroomheid leer, want die katkisant moet by die aflê van die geloofsbelydenis ook sy persoonlike geloof bely. Niesel (1934-1935:305) stel na aanleiding van Calvyn se reëlings in hierdie verband:

Die Konfirmation hat vielmehr allein den Zweck, die Kinder, auf die Gott durch die Taufe seine Hand gelegt hat, wieder in die Hände Gottes zu geben, in dem sie dem Abendmahl zugeleitet werden...Sie (die Konfirmation) ist nicht der Ort, wo der Mensch nun etwa Gelegenheit bekäme, in sachen des göttlichen Gnadenbundes mitzureden, sondern ein Anlasz, um ihm deutlich zu machen, dass er ganz und gar auf Gottes Wort als Quelle des Lebens angewiesen ist.

Dit sou kon gesê word dat by Calvyn ook in hierdie verband die klem op die objektiewe lê terwyl dit by Bucer meer subjektief is. Dit is dan veral interessant dat Calvyn se standpunt so weinig navolging gevind het. In ieder geval is dit duidelik dat Calvyn die belydenis van geloof deur die katkisant koppel met die twee sakramente, doop en nagmaal. Die kinderdoop lê op die ouers èn die dopeling die plig om deur middel van die kategese te beweeg na die openbare geloofsbelydenis in die midde van die gemeente. Dit is deel van die gehoorsaamheid wat die genadeverbond oplê. Net so is daar 'n direkte koppeling tussen die geloofsbelydenis en die nagmaal, want die geloofsbelydenis, voorafgegaan deur die kategese, open die weg na die nagmaal. Hierdie hele beweging het volgens Calvyn net een doel, naamlik die sola ecclesiae aedificatio (OC L 152 Komm II Kor 13:7) en die doctrinae assiduitas (OC LII 158 Komm I Thess 3:10).

\section{SLOTOPMERKING}

As Calvyn in Genève hom besig hou met die oprigting van die kerk, dan moet hy aandag gee aan wie die kerk is. Omdat die kinders van die gelowiges deur die doop die bevestiging ontvang het dat hulle lidmate van die kerk is (Institusie 1559 IV.16.5-7), gee hy ook aandag aan die vraag hoe hulle sal bely dat hulle soos en saam met die kerk in dieselfde God en Christus glo. Die antwoord is dan dat deur 
middel van die kategese die kinders gelei moet word na 'n openbare geloofsbelydenis en die daaropvolgende deelname aan die nagmaal. Die basis waarop dit alles rus is die genadeverbond, want die katkisante se geloofsbelydenis is 'n verbondshandeling omdat dit op die doop volg en na die nagmaal lei. Daarom het Calvyn ook soveel aandag daaraan gegee en dit so sorgvuldig gestruktureer dat dit inderdaad 'n duidelike kerklike tradisie geskep het wat tot vandag nog gevolg word.

\section{Literatuurverwysings}

Brunner, P 1925. Vom Glauben bei Calvin. Tübingen.

Herminjard, A L 1878-1897. Correspondence des Reformateurs. Genève-Paris. Jacobs, P 1949. Reformierte Bekenntnissschriften und Kirchenordnungen in deutscher Uebersetzung. Neukirchen: Neukirchener Verlag.

Kampschulte, F W 1869. Johann Calvin: Seine Kirche und sein Staat in Genf, Bd 1. Leipzig.

Niesel, W 1934/1935. Die Konfirmation nach einen reformatorischen Formular. Evangelische Theologie 1.

Parker, T H L 1975. John Calvin: A biography. London: J M Dent \& Sons Ltd.

Peter, R 1965. L'abécédaire genevois ou catéchisme élémentaire de Calvin, in Regards contemporains sur Jean Calvin. Paris: Presses Universitaires de France.

--- 1974. Le Premier ouvrages francais imprimés à Strasbourg, in Extrait de L'Annuaire des Amis Vieux-Strasbourg. Strasbourg.

Pfisterer, E 1938. Vorwort, in Niesel, W, Bekenntnisschriften und Kinchenordnungen der nach Gottes Wort reformierten Kirche. Zollikon-Zürich: Evangelische Verlag A G.

Pont, A D 1981. Die historiese agtergronde van ons kerklike reg, Deel 1. Pretoria: HAUM.

Richter, A L 1846. Die evangelische Kirchenordnungen des sechszehnten Jahrhunderts, Bd 1. Weimar.

Rilliet, A et Dufour, Th 1878. La catechisme francais de Calvin. Genève.

Schwarz, R 1962. Johannes Calvins Lebenswerk in seinen Briefen, Bd 1. Neukirchen: Neukirchener Verlag.

Simpson, H W 1981. Calvyn se kategismus in Afrikaans vertaal. Potchefstroom: Potchefstroomse Teologiese Publikasies.

Stupperich, R (hrsg) 1987. Martin Bucers Katechismus aus den Jahren 1534, 1537, 1543 in Martin Buceri Opera Omnia, Series I. (Deutsche Schriften, Bd 7.) Gütersloh-Paris: Gütersloher Verlaghaus Gerd Mohn.

Van 't Veer, M B 1942. Catechese en catechetische stof bij Calvijn. Kampen: Kok. 